\title{
PANORAMA NORMATIVO-JURISPRUDENCIAL DO ELEMENTO DE EMPRESA: UMA ANÁLISE DO REGIME JURÍDICO DO PRESTADOR DE SERVIÇOS INTELECTUAIS À LUZ DOS TRIBUNAIS
}

\author{
NORMATIVE AND JURISPRUDENCIAL OVERVIEW OF THE BUSINESS \\ ELEMENT: AN ANALYSIS OF THE LEGAL FRAMEWORK OF INTELLECTUAL \\ SERVICES PROVIDER IN THE LIGHT OF THE COURTS
}

\author{
${ }^{1}$ Rodolpho Barreto Sampaio Júnior \\ ${ }^{2}$ Daniella Bernucci Paulino
}

\section{RESUMO}

Trata-se de pesquisa acerca da interpretação dada pelos Tribunais de Justiça de Minas Gerais e São Paulo e pelo Superior Tribunal de Justiça ao termo elemento de empresa, previsto no art. 966, parágrafo único, do Código Civil Brasileiro. O objetivo do trabalho é analisar e compreender os critérios adotados pelos tribunais para enquadrar o prestador de serviços intelectuais como empresário. A partir de uma abordagem qualitativa adotou-se o método de análise documental, o que permitiu o estudo e a categorização dos fundamentos empregados pelos tribunais na apreciação dos casos concretos, contribuindo para a formação de um conceito jurisprudencial de elemento de empresa.

Palavras-chave: Direito empresarial, Empresário, Elemento de empresa

\section{ABSTRACT}

This is a study about the interpretation given by the Courts of Justice of Minas Gerais and Sao Paulo and the Superior Court of Justice to the term business element, laid down in art. 966, sole paragraph, of the Brazilian Civil Code. The objective is to analyze and understand the criteria adopted by the courts to frame the intellectual service provider as an entrepreneur. From a qualitative approach was adopted documentary analysis method, which allowed the study and categorization of the reasons used by the courts in examining individual cases, contributing to the consolidation of a jurisprudential concept of business element.

Keywords: Business law, Entrepreneur, Business element

\footnotetext{
${ }^{1}$ Doutor em Direito pela Universidade Federal de Minas Gerais - UFMG, Minas Gerais, MG, (Brasil). Professor na Pontifícia Universidade Católica de Minas Gerais - PUC Minas, Minas Gerais.(Brasil). E-mail: rodolpho.sampaiojr@gmail.com

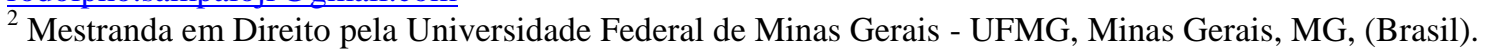
Professora na Pontifícia Universidade Católica de Minas Gerais, PUC Minas, Minas Gerais.(Brasil). E-mail: daniella.bernucci@gmail.com. 


\section{INTRODUÇÃO}

Jacques Le Goff (2013, p. 115) afirma que toda sociedade tem sua hierarquia social, reveladora de suas estruturas e mentalidades. Segundo o historiador francês, "ofícios nobres, ofícios vis, ofícios lícitos, ofícios ilícitos, essas categorias abrangem as realidades econômicas e sociais e mais ainda as mentalidades".

Não é difícil perceber que muitas dessas mentalidades e tabus, forjados nas sociedades primitivas e medievais, deixam marcas que se perpetuam íntegras, atenuadas ou modificadas, até os dias de hoje, moldando, por certo, o ordenamento jurídico.

Se o desprezo pelo labor e pelo lucro vão se esmaecendo a partir do século XII e se o bem comum passa a justificar a busca pelo lucro, tão cara ao mercador, certo é que sempre se viu a atividade mercantil com certo desprezo e desconfiança. (LE GOFF, 1991, p. 71-76).

Santo Tomás de Aquino registra essa mudança de postura ao afirmar que "quando alguém se entrega ao comércio tendo em vista a utilidade pública, quando se vê que as coisas necessárias à existência não faltam em um país, o lucro em vez de ser visado como fim, é somente reclamado como remuneração do trabalho". (LE GOFF, 2013, p. 128).

Muitos séculos se passaram... Os mercadores medievais se tornaram empresários com alcance planetário. Consolidada a burguesia mercantil como classe dominante no capitalismo (que se transmudou de mercantil a industrial e, após, de industrial a financeiro e de serviços, e de local a global), finalizado o preconceito contra o labor e a exaltação medieval do ócio, e acertada, na esfera do direito, a predominância da noção de empresa, permanece, como réstia de um traço histórico, a separação entre atividades econômicas organizadas e não organizadas e, de certa forma, ainda se distinguem os lucros dos honorários.

Nesse sentido, na esteira e inspiração sorvida do Codice Civile, prevê o direito brasileiro que não se caracteriza como empresário o profissional liberal, ou seja, aquele que exerce uma profissão intelectual.

O propósito deste artigo não se centra na avaliação da adequação ou não de tal exclusão, alicerçada em conceito historicamente construído. Considerando o direito nacional posto, o que se pretende é compreender e interpretar o art. 966 do Código Civil Brasileiro de 2002, especialmente seu parágrafo único.

Nessa temática, a interpretação da letra da lei e do seu espírito produziu vasta bibliografia estrangeira e nacional. Juristas de expressão se desdobraram sobre os termos 

profissão intelectual, natureza artística, literária, científica e elemento de empresa, dentre outros necessários à compreensão do teor do texto legal em discussão.

Os antecedentes que fundamentaram o artigo do Código, as escolhas que o mesmo implica e a sua fórmula final foram exaustivamente analisados, gramatical e teologicamente. Tudo para se concluir que poderá o exercente de profissão intelectual ser ou não tratado como empresário, dependendo essa definição de sua ação constituir ou não elemento de empresa.

Ora, fica assim patente que essa caracterização, esse enquadramento e equiparação, quiçá essa transformação do profissional liberal em “mercador” dependerá da análise, sempre, das condições do exercício de sua atividade, ou seja, da apreciação do caso concreto.

Por esse motivo, apesar de reconhecer-se que "assim como a saúde não se define pela doença, o direito não se reduz ao contencioso" (ROULAND, 2003, p. 7) o objetivo deste artigo é, nesse vaivém de ideias, analisar, dentro de limites estabelecidos, como vêm os tribunais interpretando, na prática, o elemento de empresa inserido no ordenamento pátrio pelo Código Civil de 2002.

Apesar da regra do art. 966 do Código Civil não ser ambígua, quando posta à interpretação pelo Judiciário, sua clareza formal nem sempre resulta em parâmetros similares. Reside, pois, a relevância desta pesquisa, em conhecer esses parâmetros dos julgadores e construir, em prol da segurança jurídica, tão relevante às atividades negociais, um conceito jurisprudencial de elemento de empresa.

Começa-se o desenvolvimento do trabalho com breves considerações teóricas sobre o elemento de empresa. Segue-se com a descrição dos critérios utilizados para selecionar os julgados e os resultados obtidos. Em seguida, faz-se o levantamento das principais ideias veiculadas nas decisões, para em sequência se propor um conceito jurisprudencial de elemento de empresa. Metodologicamente, a pesquisa utilizou uma abordagem qualitativa, e o método de pesquisa empregado foi o da análise documental com a coleta de dados consistentes em textos especializados e acórdãos de três distintos tribunais. A partir daí, foi feita a análise de conteúdo, seguindo-se as etapas de pré-análise dos documentos apurados, sua seleção e escolha; por fim, foi feita a categorização e tratamento dos dados.

\section{O ELEMENTO DE EMPRESA COMO CONCEITO ESTRUTURANTE DO DIREITO EMPRESARIAL}


A substituição da expressão direito comercial por direito empresarial não é apenas semântica. Na realidade, ela reflete a inclusão de um novo elemento nesse ramo do direito privado, consistente no elemento de empresa. Faz-se, pois, necessário compreendê-lo adequadamente, a fim de apreender os precisos limites e o correto alcance do direito empresarial.

\subsection{ANÁliSE DOUTRINÁRIA DO ART. 966, PARÁGRAFO ÚNICO, DO CÓdigo CIVIL}

Os conceitos de empresa e empresário foram estabelecidos pelo art. 966 do Código Civil, inserido no Título I do Livro II, Do Direito de Empresas (BRASIL,2003):

Art. 966. Considera-se empresário quem exerce profissionalmente atividade econômica organizada para a produção ou a circulação de bens ou de serviços.

Parágrafo Único. Não se considera empresário quem exerce profissão intelectual, de natureza científica, literária ou artística, ainda com o concurso de auxiliares ou colaboradores, salvo se o exercício da profissão constituir elemento de empresa.

Sob o olhar da doutrina brasileira e italiana, determina esse artigo uma clara divisão entre as atividades econômicas. De um lado têm-se aqueles que produzem ou circulam bens e serviços de forma organizada, incluídos, sem sombra de dúvida, os prestadores de serviços intelectuais; de outro se tem os prestadores de serviços intelectuais que não utilizam a opera intellettuale como parte de uma empresa.

MALATESTA (1998, p. 175) afirma que

a jurisprudência é firme em excluir a prestação de serviços intelectuais típica dos profissionais liberais, considerando que não se trata de atividade de empresa, dado o caráter personalista da prestação e a relação de fidúcia, própria desse gênero de atividade, que se estabelece entre o prestador e o seu cliente.

Para o autor, ao distinguir o trabalho autônomo e o trabalho na empresa, o Código Italiano estabelece que

o que conta e prevalece e caracteriza a importância e o valor, é sempre o trabalho intelectual do sujeito, é ele que atua no desenvolvimento de sua atividade, não por sua própria iniciativa, como na empresa, mas com base em um compromisso fiduciário (intuitu personae) com o cliente, concluído predominantemente com trabalho próprio e sem o vínculo de subordinação. (MALATESTA, 1998, p. 185).

Mas, logo em seguida, continua: 
Mas, a jurisprudência é pacífica em aceitar que o desenvolvimento de uma atividade intelectual pode se juntar, integrar ou concorrer para o exercício de uma empresa, segundo o art. 2238, Código Civil. Nesse caso, aplicam-se as regras da atividade empresarial e as sobre a profissão liberal. (MALATESTA, 1998, p. 186).

Ilustra sua explicação o autor, relatando um caso julgado pelo Tribunal de Avelino, em 13 de agosto de 1953: "a corte decidiu, com base no art. 2238, que um médico que exercesse sua profissão e também gerisse uma clínica, poderia ser tratado como médico e como empresário”. (MALATESTA, 1998, p. 186).

$\mathrm{Na}$ mesma linha, os doutrinadores brasileiros, dentre os quais se destaca BORBA (2003), estabelecem que a linha que separa empresários e não empresários está na organização:

É, por conseguinte, a estrutura organizacional que vai distinguir o trabalhador autônomo do empresário. O autônomo exerce sua atividade econômica de forma pessoal, ou com a colaboração de auxiliares subalternos ou até mesmo de outros profissionais, mas o que prevalece é o seu trabalho pessoal [...] a empresa existe quando as pessoas coordenadas ou os bens materiais utilizados, no concernente à produção ou à prestação de serviços, operados pela sociedade, suplantam a atuação pessoal dos sócios.

No que cinge ao trabalho intelectual, não se discute que o parágrafo único é uma exceção à regra geral, prevista para caracterização da prestação de serviços. Nesse caso, por força de tradições socioculturais e motivações históricas, está o prestador de serviços intelectuais apartado da noção de empresa, justamente por se ver no seu trabalho uma criação da mente. De fato, "a sua criação, por ser uma emanação do espírito, não seria assimilável aos chamados processos produtivos". (BORBA, 2003).

Também assim descreve ABREU (1999, p. 98-103) ao tratar do tema no direito português:

Não há critério unívoco de profissão liberal. Consideraremos como tal a que se traduz no exercício habitual e autónomo (juridicamente não subordinado) de actividades primordialmente intelectuais, susceptíveis de regulamentação controlo próprios. [...] Os profissionais liberais não são comerciantes - não fazem do "comércio" profissão [...] Aqui e ali, continua hoje a falar-se genericamente de empresas de profissionais liberais, mais precisamente de "estabelecimentos de 
exercício de profissão liberal”. Contudo, parece mais ajustado sustentar, que, em regra, os escritórios, consultórios, estúdios dos

profissionais liberais não constituem empresas. O que aí avulta é a pessoa dos profissionais (com específica capacidade técnico-científica para a prestação de serviços) não um objectivo complexo produtivo; o conjunto dos instrumentos de trabalho não têm autonomia funcional nem identidade própria, não mantem idêntica "eficiência" ou "produtividade" na titularidade de terceiro (profissional da mesma especialidade); a actividade do sujeito exaure praticamente todo o processo produtivo (prestação de serviços" [...] Em regra, portanto, não há aqui empresas. Mas pode haver.

A dúvida, lançada por ABREU (1999, p. 103), descortina a pergunta fundamental, que surge a partir da leitura da segunda metade do parágrafo único do art. 966 do Código Civil: quando e como se torna o trabalho intelectual elemento de empresa?

Teoricamente, pode-se dizer que sempre que o serviço intelectual se tornar uma peça, um componente, uma parte de uma atividade empresária e não mais o próprio serviço prestado. Enfim, pode-se entender que há a despersonalização da atividade intelectual cientifica, literária ou artística. Esta, como criação do intelecto, deixa de ser centro da atividade, tornando-se um elemento de uma atividade empresarial que a suplanta. Na medida em que ela perde esse caráter intuitu personae justifica-se a sua inclusão no rol das atividades econômicas empresariais.

Dando sequência ao raciocínio, cumpre indagar: qual a relevância de ser empresário no direito nacional?

Basicamente, pode-se dizer que a especialidade do direito comercial que o acompanha desde sua origem, na famosa dicotomia do direito privado, determina que a esse grupo de pessoas (ou atos, conforme a fase histórica que se aprecie) se apliquem regras próprias, conhecidas hoje como regime jurídico empresarial.

Pois bem. Com a unificação do direito obrigacional brasileiro, pode-se afirmar que, fundamentalmente, o que separa empresários e não empresários é a submissão a um regime jurídico especial de falência e recuperação de empresa. Há, ainda, questões tributárias como, por exemplo, a aplicação de alíquotas diferenciadas para atividades empresariais e atividades não empresariais, mas na seara estrita do direito de empresarial é a possibilidade de utilização dos institutos falência e recuperação de empresas que se faz realmente significativa. 


\title{
2.2 CRITÉRIOS DE ANÁLISE DA JURISPRUDÊNCIA
}

\author{
Assevera FIUZA (2003, p. 197) que
}

essa oração [se o exercício da profissão constituir elemento de empresa, ressalva da parte final do parágrafo único do art. 966 do Código Civil] vem causando sérias dificuldades para sua compreensão. Com base nela tem-se sustentado que o exercício de atividade intelectual estruturada e organizada, produzida em volume expressivo, caracteriza a pessoa que a exerce como empresário.

Posto o problema, com o objetivo de compreender como se deu, por parte dos tribunais nacionais, a partir da promulgação do Código Civil de 2002, a interpretação do termo "elemento de empresa" foram analisados 61 acórdãos julgados pelo Tribunal de Justiça de Minas Gerais, do período de 2005 a 2015. Dos 61 acórdãos obtidos, 03 eram pertinentes para a pesquisa, sendo os demais, por conseguinte, descartados. Em seguida, foram analisados

88 acórdãos do TJSP, do período de 2004 a 2015. Dos 88 acórdãos obtidos, 10 eram pertinentes para a pesquisa, sendo os demais, por conseguinte, descartados. Também foram examinados 07 acórdãos do Superior Tribunal de Justiça, do período de 2010 a 2015. Dos 07 acórdãos obtidos, 03 eram pertinentes para a pesquisa, sendo, por conseguinte 04 deles descartados.

Ao todo foram analisados 156 acórdãos. Desses, 16 discutiam o alcance do termo "elemento de empresa" sob a perspectiva do direito empresarial. Os demais foram descartados por não ter relação direta com o tema. Dentre esses se encontravam vários julgados que tratavam do regime de tributação diferenciada aplicado às sociedades uniprofissionais que não possuem caráter empresarial. Esses, embora citem o art. 966, parágrafo único, do Código Civil, e tratem da questão da caracterização do serviço intelectual como elemento de empresa, o fazem na perspectiva de análise da tributação do ISSQN, considerando variáveis próprias da legislação tributaria federal e municipal específica.

Nos três tribunais, esses acórdãos foram localizados a partir do termo "elemento de empresa" como palavra de busca no inteiro teor dos mesmos.

\subsection{ANÁLISE DOS ACÓRDÃOS}

Da leitura dos acórdãos selecionados, resta claro que a análise dos tribunais se baseia em comprovação fática, ou não, da transformação de uma atividade consistente em profissão intelectual em um elemento de uma atividade empresarial. 
Assim, se no caso, o conjunto probatório permite chegar à conclusão pretendida pelo autor ou, se ao contrário, ilide essa pretensão, o tribunal qualifica o exercente da atividade: empresário ou profissional liberal autônomo; sociedade empresária ou sociedade simples (uni ou multiprofissional).

Deixa clara essa necessidade imperativa de se conhecer a sociedade de perto, avaliando-se cada caso em suas circunstâncias concretas, o Superior Tribunal de Justiça, no voto do Relator, Ministro João Otávio de Noronha, no julgamento do Recurso Especial, n. ${ }^{\circ}$ 958.116, em que se analisa a delicada questão de inclusão, ou não, do fundo de comércio na apuração de haveres de uma sociedade de engenheiros, ao afirmar a relevância de se avaliar qual é a real posição da sociedade no mercado (BRASIL, 2012):

[...] Cada caso deve ser mensurado particularmente, no sentido de se aferir se, realmente, existe o goodwill ou se os valores incorpóreos acompanham as pessoas dos sócios. Portanto, é de suma importância para o deslinde da questão discutida nos autos que se saiba, de fato, e não só pelo ato constitutivo da sociedade, qual sua real posição no mercado. Em outras palavras, é preciso avaliar se o nome Tesc - Consultoria e Projetos Estruturais compõe um fundo de comércio de fato ou se diz respeito a uma sociedade de prestação de serviços profissionais dos sócios que a compõem.

O ponto chave é a despersonalização da prestação centrada na criação intelectual. Esta, que seria prestada pessoalmente, o deixa de ser. Assim, torna-se uma engrenagem na organização dos fatores de produção. Nesse sentido, a questão que se põe é, justamente, quais seriam os fatores que objetivamente indicariam essa alteração na estrutura da atividade. E, principalmente, se esses fatores poderiam ser aplicados em todo e qualquer caso julgado.

Após a leitura dos acórdãos, pode-se organizá-los da seguinte maneira:

\begin{tabular}{|c|c|c|c|c|c|c|}
\hline $\begin{array}{l}\text { TRIBU } \\
\text { NAL }\end{array}$ & RECURSO & $\begin{array}{l}\text { DATA DO } \\
\text { JULGAMEN } \\
\text { TO }\end{array}$ & AÇÃO & $\begin{array}{l}\text { SERVIÇOS } \\
\text { PRESTADO } \\
\text { S }\end{array}$ & $\begin{array}{l}\text { ENQUA } \\
\text { DRAME } \\
\text { NTO } \\
\text { PELO } \\
\text { TRIBUN } \\
\text { AL }\end{array}$ & $\begin{array}{l}\text { FUNDAMEN } \\
\text { TAÇÃO } \\
\text { PRINCIPAL }\end{array}$ \\
\hline TJMG & $\begin{array}{l}\text { Agravo de } \\
\text { Instrumento- } \\
\text { Cv 1.0024.09.498 } \\
126- \\
3 / 001 \quad 4981263 \\
- \\
37.2009 .8 .13 .002 \\
4(1)\end{array}$ & 01.01 .2010 & $\begin{array}{l}\text { Dissolução } \\
\text { de } \\
\text { sociedade e } \\
\text { apuração de } \\
\text { haveres }\end{array}$ & Advocatícios & Simples & $\begin{array}{l}\text { Por força de } \\
\text { lei especifica a } \\
\text { advocacia } \\
\text { nunca é } \\
\text { empresarial. }\end{array}$ \\
\hline
\end{tabular}




\begin{tabular}{|c|c|c|c|c|c|c|}
\hline STJ & $\begin{array}{l}\text { Recurso Especial } \\
\mathrm{n}^{\mathrm{o}} 1.227 .240-\mathrm{SP} \\
(20100230258-0)\end{array}$ & 26.05 .2015 & $\begin{array}{l}\text { Dissolução } \\
\text { de } \\
\text { sociedade e } \\
\text { apuração de }\end{array}$ & Advocatícios & Simples & $\begin{array}{l}\text { Por força de } \\
\text { lei especifica a } \\
\text { advocacia } \\
\text { nunca é }\end{array}$ \\
\hline & & & haveres & & & empresarial. \\
\hline TJSP & $\begin{array}{l}\text { Apelação Cível n } \\
\text { o 9125361- } \\
30.2007 .8 .26 .000 \\
0\end{array}$ & $28 / 05 / 2008$ & $\begin{array}{l}\text { Pedido de } \\
\text { Falência }\end{array}$ & Cobrança & Empresa & $\begin{array}{l}\text { Não se trata de } \\
\text { serviço } \\
\text { intelectual. }\end{array}$ \\
\hline STJ & $\begin{array}{l}\text { Recurso Especial } \\
\mathrm{n}^{\circ} \quad 1.266 .666 \text { - SP } \\
(20090196940-9)\end{array}$ & 09/08/2011 & $\begin{array}{l}\text { Extensão } \\
\text { dos efeitos } \\
\text { da falência }\end{array}$ & Contábeis & Empresa & $\begin{array}{l}\text { Porte } \\
\text { econômico do } \\
\text { prestador }\end{array}$ \\
\hline STJ & $\begin{array}{l}\text { Recurso Especial } \\
\mathrm{n}^{\circ} \text { 958.116 - PR } \\
(20070125095-0)\end{array}$ & $22 / 05 / 2012$ & $\begin{array}{l}\text { Dissolução } \\
\text { de } \\
\text { sociedade e } \\
\text { apuração de } \\
\text { haveres }\end{array}$ & Engenharia & Simples & $\begin{array}{l}\text { O serviço } \\
\text { intelectual não } \\
\text { se tornou } \\
\text { elemento de } \\
\text { empresa e a } \\
\text { sociedade não } \\
\text { é voltada para } \\
\text { o mercado }\end{array}$ \\
\hline TJSP & $\begin{array}{l}\text { Agravo de } \\
\text { Instrumento } \mathrm{n}^{\mathrm{o}} \\
\text { 0170959- } \\
\text { 53.2013.8.26.000 } \\
0\end{array}$ & $06 / 02 / 2014$ & $\begin{array}{l}\text { Recuperaçã } \\
\text { o judicial }\end{array}$ & Médicos & Empresa & $\begin{array}{l}\text { Porte } \\
\text { econômico }\end{array}$ \\
\hline TJSP & $\begin{array}{l}\text { Agravo de } \\
\text { Instrumento } \mathrm{n}^{\mathrm{o}} \\
\text { 2023917- } \\
63.2013 .8 .26 .000 \\
0\end{array}$ & $09 / 12 / 2013$ & $\begin{array}{l}\text { Recuperaçã } \\
\text { o judicial }\end{array}$ & Médicos & Empresa & $\begin{array}{l}\text { Porte } \\
\text { econômico }\end{array}$ \\
\hline TJSP & $\begin{array}{l}\text { Apelação Civel no } \\
9196206- \\
92.2004 .8 .26 .000 \\
0\end{array}$ & $08 / 09 / 2005$ & $\begin{array}{l}\text { Pedido de } \\
\text { falência }\end{array}$ & Médicos & Simples & $\begin{array}{l}\text { Não foi feita a } \\
\text { prova de que a } \\
\text { sociedade de } \\
\text { atividade } \\
\text { tipicamente } \\
\text { intelectual era } \\
\text { empresarial. }\end{array}$ \\
\hline TJSP & $\begin{array}{l}\text { Apelação Civel } n^{\circ} \\
0122177- \\
84.2005 .8 .26 .010 \\
0\end{array}$ & $07 / 11 / 2013$ & $\begin{array}{l}\text { Apuração } \\
\text { de haveres }\end{array}$ & Médicos & Empresa & $\begin{array}{l}\text { Não há } \\
\text { pessoalidade, } \\
\text { mas sim } \\
\text { massificação } \\
\text { dos serviços e } \\
\text { ênfase na } \\
\text { estrutura. }\end{array}$ \\
\hline TJSP & $\begin{array}{l}\text { Apelação Cível } n^{\circ} \\
\text { 0035290- } \\
\text { 72.2006.8.26.000 } \\
0\end{array}$ & $22 / 08 / 2006$ & $\begin{array}{l}\text { Pedido de } \\
\text { falência }\end{array}$ & Médicos & Simples & $\begin{array}{l}\text { Não tem } \\
\text { finalidade } \\
\text { lucrativa } \\
\text { (filantrópica). }\end{array}$ \\
\hline TJSP & $\begin{array}{l}\text { Agravo }^{\circ} \\
311.752 .4 / 0-00\end{array}$ & $01 / 06 / 2004$ & $\begin{array}{l}\text { Pedido de } \\
\text { falência }\end{array}$ & $\begin{array}{l}\text { Médicos e } \\
\text { outros }\end{array}$ & Empresa & $\begin{array}{l}\text { Não se trata de } \\
\text { serviço } \\
\text { intelectual. }\end{array}$ \\
\hline
\end{tabular}


Panorama Normativo-Jurisprudencial do Elemento de Empresa: uma Análise do Regime Jurídico do Prestador de Serviços Intelectuais à Luz dos Tribunais

\begin{tabular}{|l|l|l|l|l|l|l|}
\hline TJSP & $\begin{array}{l}\text { Apelação Cível no } \\
\text { 0045261- } \\
62.2012 .8 .26 .010 \\
0\end{array}$ & $06 / 05 / 2013$ & $\begin{array}{l}\text { Pedido de } \\
\text { falência }\end{array}$ & educacionais & Empresa & $\begin{array}{l}\text { Diversificação } \\
\text { de atividades } \\
\text { desenvolvidas } \\
\text { demonstra a } \\
\text { empresarialida }\end{array}$ \\
\hline
\end{tabular}

\begin{tabular}{|c|c|c|c|c|c|c|}
\hline & & & & & & de. \\
\hline TJSP & $\begin{array}{l}\text { Agravo de } \\
\text { Instrumento } \mathrm{n}^{\circ} \\
0187821- \\
36.2012 .8 .260000\end{array}$ & $25 / 03 / 2013$ & $\begin{array}{l}\text { Pedido de } \\
\text { falência }\end{array}$ & educacionais & Empresa & $\begin{array}{l}\text { Organização } \\
\text { para o } \\
\text { mercado. }\end{array}$ \\
\hline TJSP & $\begin{array}{l}\text { Apelação Cível no } \\
990.10 .092657-8 .\end{array}$ & $20 / 05 / 2010$ & $\begin{array}{l}\text { Pedido de } \\
\text { falência }\end{array}$ & educacionais & Simples & $\begin{array}{l}\text { O serviço } \\
\text { intelectual não } \\
\text { se tornou } \\
\text { elemento de } \\
\text { empresa }\end{array}$ \\
\hline TJMG & $\begin{array}{l}\text { Agravo de } \\
\text { Instrumento } 1.002 \\
4.05 .812057- \\
7 / 001 \quad 8120577 \\
- \\
83.2005 .8 .13 .002 \\
4(1)\end{array}$ & 14.09 .2006 & $\begin{array}{l}\text { Pedido de } \\
\text { falência }\end{array}$ & Vigilância & Empresa & $\begin{array}{l}\text { Não se trata de } \\
\text { serviço } \\
\text { intelectual. }\end{array}$ \\
\hline TJMG & $\begin{array}{l}\text { Apelação } \\
\text { Cível 1.0024.05.8 } \\
44559- \\
4 / 002 \quad 8445594 \\
- \\
48.2005 .8 .13 .002 \\
4(1)\end{array}$ & 08.03 .2012 & $\begin{array}{l}\text { Pedido de } \\
\text { insolvência } \\
\text { civil }\end{array}$ & vigilância & Empresa & $\begin{array}{l}\text { Não se trata de } \\
\text { serviço } \\
\text { intelectual. }\end{array}$ \\
\hline
\end{tabular}

Esses dados podem ser mais bem visualizados das seguintes formas:

\section{Tipo de Ação Proposta}

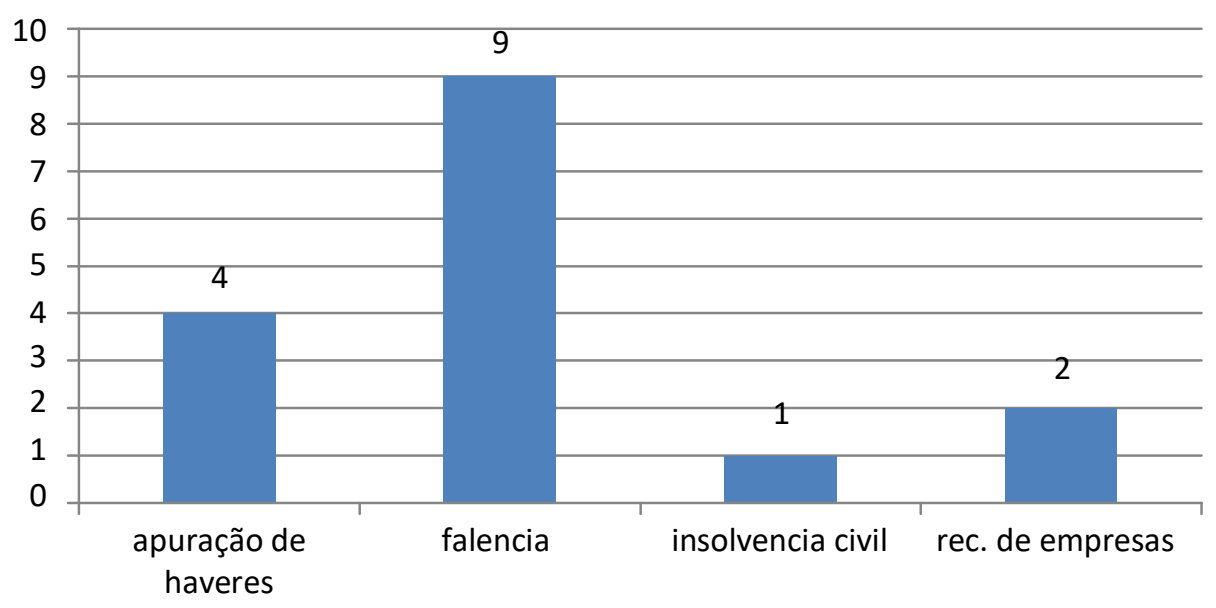



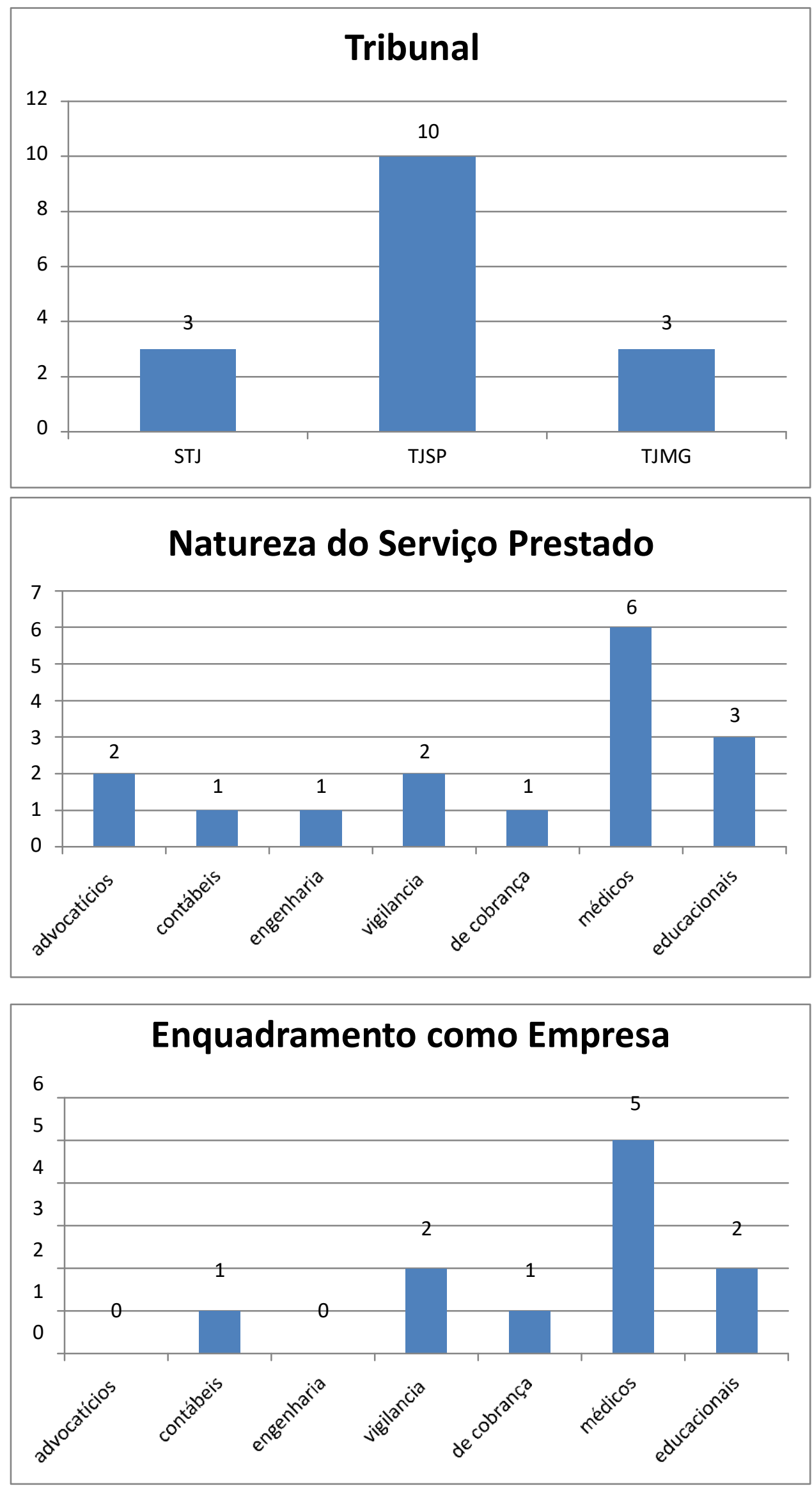


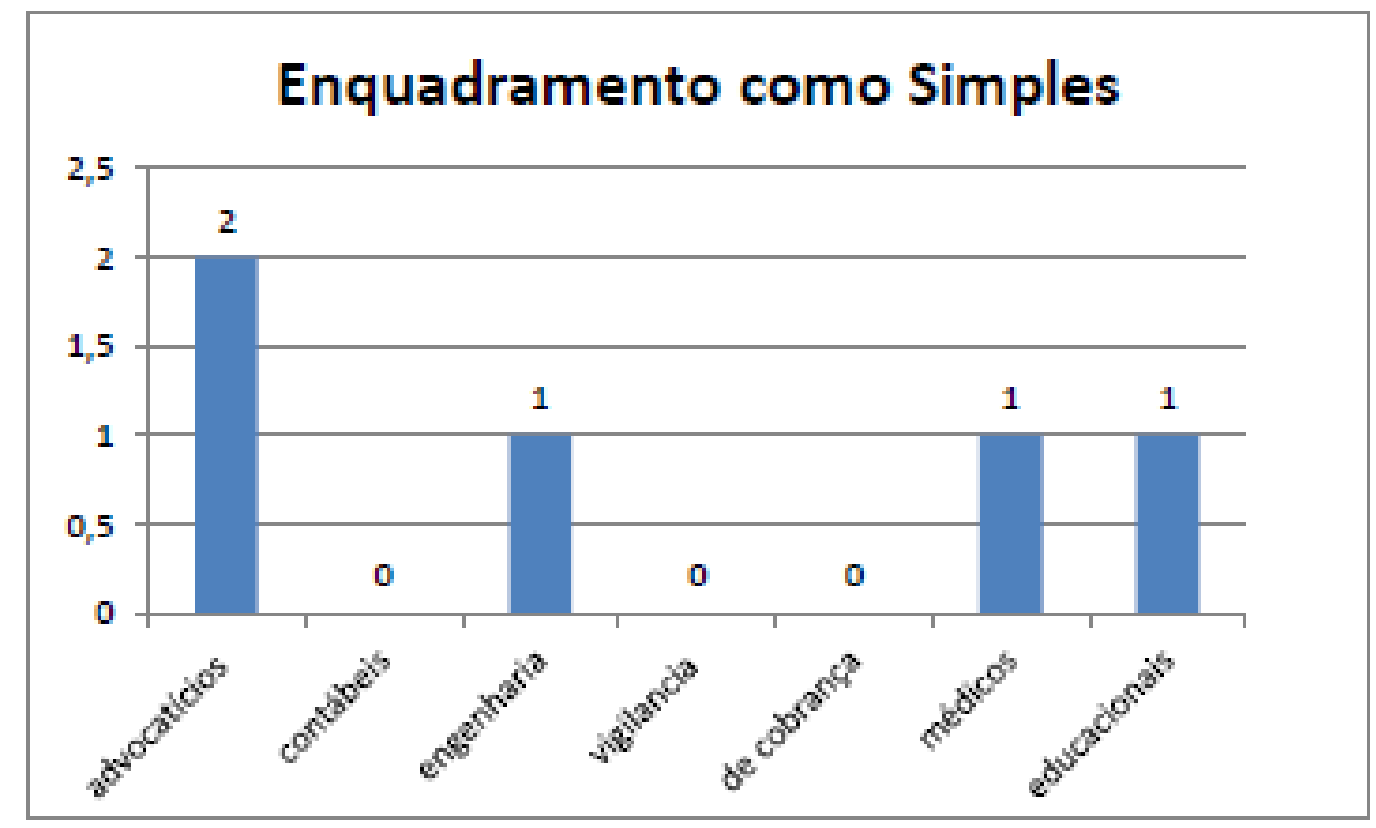

Também, pelo exame de seu inteiro teor, pode-se elencar alguns pontos comuns que se destacam na jurisprudência desses três tribunais.

\subsubsection{OBJETIVO DE LUCRO}

Um primeiro ponto reside na apreciação do escopo lucrativo da atividade. Todos os julgados analisados que trataram desse ponto afirmam que o objetivo de lucro não atribui a ninguém a condição de empresário. Na verdade, se reconhece que ter lucro é o objeto de toda e qualquer atividade econômica, seja ela organizada ou não na forma de empresa.

Estabelece, nesse sentido, o STJ, no RESP n 1.227.240 (BRASIL, 2015):

Nessa linha, ressai nítida a grande diferença entre as sociedades simples e as sociedades empresárias, que não está no fato de uma possuir finalidade lucrativa e a outra não. O que realmente distingue uma sociedade empresária de uma sociedade simples é o objeto social. A sociedade empresária tem por objeto o exercício de empresa (atividade econômica organizada de prestação ou circulação de bens ou serviços); enquanto a sociedade simples tem por objeto o exercício de atividade econômica não empresarial.

De outra parte, é evidente que se não há escopo de lucro não há que se falar nem em atividade econômica, muito menos em atividade econômica empresarial. Nesse aspecto, são curiosos alguns acórdãos que apreciam pedidos de falência de "Santa Casa de Misericórdia". 
Dentre eles, a Apelação Cível n. 450.293.4/8-00, julgada pelo TJSP, na qual o Relator Des. Pereira Calças comenta que (SÃO PAULO, 2006)

em sua já longa carreira jurídica, jamais teve conhecimento de qualquer decisão judicial que tenha proclamado ser admissível decreto de falência de "Santa Casa de Misericórdia", entidades que existem em quase todas as cidades de nosso País, exercendo atividades beneficentes e filantrópicas.

\subsubsection{FORMA DE SOCIEDADE LIMITADA}

Pode-se estabelecer que entendem os tribunais que a forma ou roupagem jurídica não tem o condão de tornar empresária uma determinada pessoa. Logo, a adoção da forma limitada, no que tange às sociedades, também não é utilizada como critério. Até porque o Código Civil, ao tratar das sociedades simples, expressamente franqueia a esse tipo de sociedade não empresária a adoção da forma limitada.

Confirma essa posição o Enunciado n. 57 aprovado pela Comissão de Direito de Empresa na I Jornada de Direito Civil do Conselho da Justiça Federal (CJF, 2012): "Enunciado 57 - Art. 983: A opção pelo tipo empresarial não afasta a natureza simples da sociedade".

Na Apelação Cível n 9196206-92.2004.8.26.0000, julgada pelo TJSP, o Relator Pereira Calças explicita (SÃO PAULO, 2005):

o art. 983, do Código Civil, autoriza que as sociedades simples possam constituir-se de conformidade com um dos tipos de sociedade empresária, sendo certo que, caso se valham de tal faculdade legal, deverão inscrever-se no Registro Civil de Pessoas Jurídicas, consoante determina o art. 998 c.c. o artigo 1.150, ambos do Código Civil. Em suma, a sociedade simples que adotar o tipo legal de sociedade empresária, continua com a natureza de sociedade simples e, portanto, não pode falir, ressalvada, obviamente a hipótese da adoção do modelo sociedade por ações.

\subsubsection{REGISTRO NA JUNTA COMERCIAL}

Em terceiro lugar, também concordam os julgadores que o registro na Junta Comercial ou no Cartório Civil de Registros é indiferente para se analisar a questão. Na 
verdade, se o registro não se fez de forma correta a consequência estará no campo da irregularidade empresarial, com os desdobramentos próprios na esfera da responsabilidade pessoal do sócio. Jamais terá o Registro na Junta Comercial o efeito de tornar uma sociedade de prestação de serviços intelectuais empresária e, por raciocínio oposto, não terá a natureza simples uma sociedade de prestação de serviços intelectuais que os utiliza como elemento de empresa, apenas porque se registrou no Registro Civil de Pessoas Jurídicas.

\subsubsection{EXCLUSÃO DOS PRESTADORES DE SERVIÇOS NÃO INTELECTUAIS}

Quarto ponto que se apresenta de forma evidente - e que consiste em uma interpretação acertada do art. 966 do Código Civil - é a desconsideração dos prestadores de serviços não intelectuais como exercentes de atividades não empresariais.

Ao examinar questões que envolvem pedidos de falência, recuperação de empresas e de insolvência civil foram, no caso das duas primeiras hipóteses, afastadas atividades como prestação de serviços de vigilância e de serviços de cobrança, considerados serviços de natureza não intelectual.

$\mathrm{Na}$ área de instituições educacionais, nas quais se discute se os serviços educacionais são de natureza intelectual, o TJSP responde afirmativamente, entendendo que essas sociedades são prestadoras de serviços intelectuais. Não obstante, em alguns casos, como no Agravo $\mathrm{n}^{\circ}$ 0187821-3620128260000 (SÃO PAULO, 2013a), na Apelação Cível n º 004526162201282600 (SÃO PAULO, 2013b) e na Apelação Cível com Revisão no 990100926578 (SÃO PAULO, 2010), atribui-se às mesmas natureza empresarial, justamente porque considera que desenvolvem suas atividades em um contexto mercadológico.

\subsubsection{Inexistência de um rol de atividades intelectuais tipicamente empresariais}

Em quinto lugar, registre-se a possibilidade de a mesma atividade ser considerada simples ou empresária. Em outras palavras, pode-se inferir, da análise dos julgados descritos, que não se trata mais de elencar um rol, enumerando, de um lado as atividades empresariais e, de outro, as simples.

Fica claro, portanto, que uma atividade tanto pode ser considerada empresarial como pode, tendo o mesmo objeto social, ser considerada simples. Exceção a essa regra são as sociedades de advogados. 
Assim, como se pode perceber, sociedades de médicos, de engenheiros, de contadores e outras profissões liberais, ora se encaixam no conceito de empresa, ora se deslocam para a esfera do direito civil, ao sabor da interpretação que se dá, no caso concreto, ao parágrafo único do art. 966 do Código Civil de 2002.

Exemplifica essa situação a existência, por exemplo, de acórdãos do TJSP que atribuem a clínicas prestadoras de serviços médicos o caráter empresarial - Agravo de Instrumento $n^{\circ}$ 0170959-53.2013.8.26.0000 (SÃO PAULO, 2014), Agravo de Instrumento $n^{\circ}$ 2023917-63.2013.8.26.0000 (SÃO PAULO, 2013c), Apelação Cível n n 012217784.2005.8.26.0100 (SÃO PAULO, 2013d) e Agravo n ${ }^{\circ}$ 311.752.4/0-00 (SÃO PAULO, 2004) - e, diante do mesmo objeto de prestação de serviços médicos o excluem (Apelação Cível no 9196206-92.2004.8.26.0000 (SÃO PAULO, 2005); Apelação Cível no 003529072.2006.8.26.0000 (SÃO PAULO, 2006). Da mesma forma, no Tribunal citado, ocorre com as entidades educacionais (Apelação Cível no 0045261-62.2012.8.26.0100 (SÃO PAULO, 2013b), Agravo de Instrumento $\mathrm{n}^{\mathrm{o}}$ 0187821-36.2012.8.260000 (SÃO PAULO, 2013a), Apelação Cível no 990.10.092657-8, (SÃO PAULO, 2010).

\subsubsection{PRESTAÇÃO DE MÚLTIPLAS ATIVIDADES}

Uma consideração adicional repousa na convicção dos tribunais em foco de que a multiplicidade de serviços prestados desnatura a prestação simples de atividades intelectuais e revela indício de organização empresarial.

Nas palavras do Relator do Recurso Especial n 1.227.240 - SP (BRASIL, 2015):

Nessa ordem de ideias, importante salientar que a sociedade simples deve se limitar ao exercício da atividade específica para a qual foi criada, relacionada à habilidade técnica e intelectual dos sócios, não podendo exercer serviços estranhos àquele mister, sob pena de configurar o elemento de empresa, capaz de transformá-la em empresária.

[...] Dessarte, as sociedades simples constituem-se com o fim precípuo de dar suporte ao exercício de determinada profissão intelectual. O patrimônio intelectual daqueles que compõem a sociedade possui papel de extrema relevância em relação aos investimentos materiais. Há evidente destaque dos esforços pessoais, quando comparados ao capital. 
Exemplifica também essa ideia a descrição do Relator Roberto Mac Craken, na Apelação Cível nº 004526162201282600 (SÃO PAULO, 2013b), ao decidir acerca do pedido de falência de entidade educacional criada para fins de treinamento:

é destacado que a Ré se firmou empresarialmente na implantação de cursos de capacitação, com unidades de treinamento instaladas em vários pontos comerciais e estratégicos no território nacional e que é detentora da tecnologia tendo desenvolvido métodos próprios de ensino de computação, montagem e operação de estabelecimentos com esse objetivo, possuindo livros, apostilas, manuais, métodos e materiais didáticos exclusivos, com ampla experiência na sua operação, todas as instalações padronizadas.

\subsubsection{PORTE ECONÔMICO}

Outra consideração comum aos tribunais para a apreciação do elemento de empresa é o porte econômico. Em várias decisões, a convicção do julgador é construída com base no porte econômico da atividade. Menciona-se, frequentemente, valor do capital social, número de credores e valores expressivos referentes ao passivo da sociedade para se conformá-la como empresarial.

Ainda que não seja expressa na lei, essa consideração é feita, não de forma absoluta, mas como um indício de que a atividade se tornou complexa e, portanto, saiu da esfera das atividades não empresariais.

No Agravo de Instrumento n. 2023917-63.2013.8.26.0000 cita o Relator (SÃO PAULO, 2013c):

Vasta descrição das atividades sociais na própria decisão agravada que dá ideia do grau de organização da sociedade, bem como de quão adiantado se encontra o procedimento de recuperação. Planilhas indicados do curso do processo que mostram, por si só, o padrão de atividade da sociedade agravada, que a despeito de ter sido constituída como simples, organiza-se como empresária, tanto que há inúmeros credores e valores expressivos em jogo.

No mesmo caso, no Agravo de Instrumento n. 0170959-53.2013.8.26.00, analisando a mesma sociedade (Neomater Ltda.) afirma-se que seu caráter empresarial decorre da "existência de inúmeros credores e passivo elevado em discussão. A complexidade estrutural que tem grande importância".

Sobre o assunto, debruça-se o Relator Francisco Loureiro (SÃO PAULO, 2014): 
A doutrina diverge acerca da interpretação [do parágrafo único do art. 966]. [...] Parte dela a utiliza para fundamentar o entendimento de que o exercício da atividade intelectual organizada de maneira que esta seja produzida em volume expressivo caracteriza o exercente como empresário [...] Na lição de Fábio Ulhoa Coelho, “a atividade típica de empresário não se define por sua atureza, mas pela forma como é explorada, quando a atividade é explorada de forma organizada (ou seja, mediante a articulação dos fatores de produção), então tem-se uma empresa [...]. Filio-me a esta parcela da doutrina, embora também tenha como correto de o caput do art. 966 do CC pressuponha a organização na sociedade simples. A despeito disso, entendo que elemento fundamental para a classificação não é a existência de organização, mas o grau dela.

\subsubsection{PESSOALIDADE}

Também o caráter pessoal da prestação é bastante citado. Consideram os tribunais que fundamental para a caracterização do prestador de serviços intelectuais como empresário é a despersonalização desses serviços intelectuais. Se a separação entre os prestadores de serviços comum e o intelectual tem como base a prestação pessoal, intuitu personae, no momento em que a pessoa do prestador se vê sublimada pela estrutura da empresa e não mais tem em seu serviço uma condição individualizada, perde o sentido a distinção.

Na Apelação Cível no 0122177-84.2005.8.26.0100, recurso examinado pelo TJSP, a AORT - Assistência Ortopédica e Traumatológica Especializada é considerada empresária, apesar de ter como objeto social a prestação de serviços médicos. (SÃO PAULO, 2013d).

Afirma o Relator, nesse caso, que caberia a inclusão do fundo de comércio no cálculo da apuração de haveres de sócio, justamente por ter a sociedade se organizado como empresa, oferecendo uma complexidade de serviços, substituindo-se o caráter individualizado por uma prestação massificada, com ênfase nos equipamentos e outros elementos estruturais.

Na mesma ordem de ideias, o STJ, ao julgar o Recurso Especial n ${ }^{\circ} 1.266 .666$ (BRASIL, 2011) sobre a extensão dos efeitos da falência a um contador, entre outros pontos da legislação falimentar, discute a caracterização do contador e outros profissionais como empresários.

Afirma a Relatora, pela análise da atividade desenvolvida, prestada por intermédio de pessoa jurídica a várias sociedades, com alto grau de know how, que os profissionais 
conceituados ofereciam seus serviços ao mercado e, portanto, embora profissionais liberais, poderiam ser considerados empresários. Veja-se:

O contador que presta serviços de administração à sociedade falida, assumindo a condição pessoal de administrador, pode ser submetido ao decreto de extensão da quebra, independentemente de ostentar a qualidade de sócio, notadamente nas hipóteses em que, estabelecido profissionalmente, presta tais serviços a diversas empresas, desenvolvendo atividade intelectual com elemento de empresa.

[...] O segundo ponto merece uma reflexão um pouco mais detida. Dizem os recorrentes que em momento nenhum exercem atividade empresária ou praticam atos de mercancia, de modo que, seja pela teoria da empresa adotada pelo CC02 e pela LF/2005, seja pela teoria dos atos de comércio adotada pelo antigo CCom e pela $\mathrm{LF} / 45$, não se enquadrariam nos conceitos de empresário ou de comerciante, imprescindíveis para a decretação de sua falência.

[...] Nesse sentido, a análise da hipótese dos autos ganha novos contornos. Não há notícias, nem no acórdão recorrido, nem no recurso especial, de que os recorrentes fossem administradores empregados da SECURINVEST. Ao contrário, o que se diz no recurso é que se trata de contadores conceituados no mercado e, especificamente com relação a CARLOS MASETTI JÚNIOR, fala-se da sua presença em conselhos fiscais e de administração de diversas companhias. É possível supor, portanto, pelas descrições feitas pelos próprios recorrentes no processo, que eles, organizados individualmente ou em sociedade, ofereciam ao mercado seus serviços, que iam, desde a constituição de empresas e elaboração de seus registros contábeis, até a administração propriamente dita dessas empresas. Trata-se, portanto, de uma atividade organizada, de um serviço prestado pelos recorrentes, mediante o emprego de significativo know how. Tanto que eles são, como aduzem em suas manifestações nos autos, profissionais conceituados no mercado.

Disso decorre que, ainda que os recorrentes, como administradores e não sócios, não sejam os investidores e empreendedores da atividade desenvolvida pela SECURINVEST, eles são, não obstante, empresários fornecedores dos serviços contábeis e de administração que afirmam prestar a essa e outras companhias. E na qualidade de prestadores desses serviços, 
podem ser qualificados como empresários e ver-se sujeitos a falência sem que isso implique qualquer violação dos arts. $1^{\circ}$ e $2^{\circ}$ da LF/45 e $1^{\circ}$ da LF/2002.

Nesse quadro, é inevitável fazer uma breve observação acerca do parágrafo único do referido art. 966 do CC02. Dispõe essa norma que "não se considera empresário quem exerce profissão intelectual, de natureza científica, literária ou artística, ainda com o concurso de auxiliares ou colaboradores, salvo se o exercício da profissão constituir elemento de empresa". Poderia-se dizer, em princípio, que os serviços contábeis prestados pelos recorrentes, justamente por se enquadrarem na referida disposição legal, impossibilitariam sua qualificação como empresários e, com isso, impediriam que lhes atingisse o decreto de falência. Mas essa ideia logo pode ser descartada na medida em que, assumindo a administração da companhia, os serviços prestados pelos recorrentes assumem claro elemento de empresa, especialmente se sua prestação for disponibilizada por intermédio de pessoa jurídica. Inexiste, nos autos, alegação de que os recorrentes atuavam e eram remunerados pela SECURINVEST como pessoas físicas.

\subsubsection{SOCIEDADES DE ADVOGADOS}

Por fim, outro ponto, examinado em um acórdão do TJMG e outro do STJ, destaca, especificamente, as sociedades de advogados. Ambos concordam que essa, por expressa disposição de lei especial (Estatuto da $\mathrm{OAB}$ ), nunca será empresária.

Afirma, nesse sentido, o STJ (BRASIL, 2015):

As sociedades de advogados são sociedades simples marcadas pela inexistência de organização dos fatores de produção para o desenvolvimento da atividade a que se propõem. Os sócios, advogados, ainda que objetivem lucro, utilizem-se de estrutura complexa e contem com colaboradores nunca revestirão caráter empresarial, tendo em vista a existência de expressa vedação legal (arts. 15 a 17, Lei n. 8.906/1994).

E, no mesmo Recurso Especial, deixa claro o STJ parte dos fundamentos históricos que inspiram a separação das atividades econômicas empresariais e não empresariais, com a distinção dos prestadores de serviços intelectuais (BRASIL, 2015): 
Ao examinar a questão, o Tribunal de Justiça do Estado de São Paulo se manifestou como a seguir (e-fls. 4.555): Sociedades de advogados não se formam para a auferição de lucros. O objetivo delas é a prestação de serviços advocatícios por vários advogados em conjunto, sobrevindo, em decorrência da atividade, o recebimento de remuneração a ser dividida entre sócios e colaboradores. Ao ser constituída, não se forma empresa com fins lucrativos que possa ser vendida ou locada. Há colaboração no trabalho e nos resultados, mas o direito aos segundos, salvo convenção em contrário, somente existe para o advogado que prestou serviços que os deram origem. Conferir a escritório de advocacia ou a sociedade de advogados o caráter de estabelecimento lucrativo é absurdo, pois depende da admissão de que eles são estabelecimentos com o objetivo de lucro. "Não faça de sua banca balcão", disse Ruy há quase um século. O conselho continua atual e a ética profissional pune quem assim age. A dignidade da nobre classe impede que se aceite a qualificação de comércio aos seus atos profissionais, única que pode justificar a formação de "estabelecimento", seja ele classificado como civil ou comercial.

Nesse sentido também é a orientação do TJMG (MINAS GERAIS, 2010), alicerçada no Estatuto da OAB:

PROCESSUAL CIVIL. AGRAVO DE INSTRUMENTO. LIQUIDAÇÃO DE QUOTAS C/C APURAÇÃO E PAGAMENTO DE HAVERES. SOCIEDADE DE ADVOGADOS. NATUREZA JURÍDICA. SOCIEDADE SIMPLES. RESOLUÇÃO 498/2006 TJMG. COMPETÊNCIA. VARA CÍVEL. DECISÃO REFORMADA.

[...]Como cediço, os membros integrantes das sociedades de advogados exercem profissão intelectual e, por isso, aquelas são qualificadas como sociedades simples, razão pela qual não se incluem na competência das varas empresariais prevista na Resolução 498/2006 deste Egrégio Tribunal de Justiça.

\section{CONCLUSÃO}

Diz, Carlos Drummond de Andrade (1979, p. 161), em belíssima poesia:

Chega mais perto e contempla as palavras.

Cada uma 
Tem mil faces secretas sobre a face neutra e te pergunta, sem interesse pela resposta, pobre ou terrível, que lhe deres:

Trouxeste a chave?

Quando se fala na disciplina atual dos prestadores de serviços intelectuais a chave está justamente em compreender do que se trata o termo "elemento de empresa".

Da investigação histórico-doutrinária empreendida pode-se concluir que o elemento de empresa será percebido sempre que a prestação de uma profissão intelectual literária, artística ou científica se despersonalizar, abandonando a marca que a separou por anos dos comerciantes e empresários: a relação intuitu personae com o cliente que se revela no foco na atividade do profissional, mentor e centro de toda realização produtiva.

Assim, deixando o serviço intelectual de sobressair e passando a ser uma peça na organização produtiva empresarial, será essa atividade considerada empresarial.

Da observação das decisões proferidas no TJMG, TJSP e STJ, no período de cerca de 10 anos, em ações que tratavam de temas afetos ao direito empresarial como falência, recuperação de empresas e dissolução de sociedades, pode-se inferir que a verificação da prática empresarial de atividades intelectuais, presumidamente não empresárias, só ocorrerá diante da verificação das condições concretas em que se desenvolveu e se desenvolve essa atividade.

Inegável que ao tratar de outros tipos de prestação de serviços - definidos aqui como não intelectuais - sequer cogitam os tribunais em considerá-las simples.

Mas, quando se adentra a esfera das atividades intelectuais, a pesquisa mostra que para esses Tribunais, que têm pontos de vista semelhantes e não apresentam pontos de discordância nos fundamentos estabelecidos em seus julgados, a atividade intelectual poderá ser efetivada por profissional liberal ou empresário; por sociedade simples ou sociedade empresária (note-se, contudo, que em todos os julgados analisados o sujeito é uma sociedade e não pessoa física).

Pois bem. A presunção é de que sendo intelectual, a atividade não será empresarial. Entretanto, para que essa convicção se mantenha, a atividade (e todas elas podem estar em uma ou em outra esfera, com exceção da prestação de serviços advocatícios) tem que ser prestada pessoalmente pelos sócios (profissionais liberais), que devem manter em si o foco da atuação. Não deve, ainda, a sociedade, terceirizar serviços ou ampliar a gama desses, extrapolando o que seria o ofício intelectual para o qual foi constituída. Mais do que isso, não 
deve a sociedade se comportar com vistas à expansão mercadológica, sendo o porte econômico e a complexidade estrutural indícios dessa vocação.

Certamente, como previsto, não é o intuito de lucro, a roupagem jurídica (sociedade limitada) ou mesmo o registro na Junta Comercial competente que terá o condão de tornar uma atividade intelectual empresária. De outra parte, não será a forma simples ou o registro civil que a manterá no campo das sociedades simples.

\section{REFERÊNCIAS}

ABREU, Jorge Manuel Coutinho de. Da Empresarialidade. As empresas no direito. Lisboa: Almedina, 1998.

ANDRADE, Carlos Drummond de. Poesia e Prosa. Rio de Janeiro: Nova Aguilar, 1979.

BORBA, José Edvaldo Tavares. Parecer do Dr. Tavares Borba. Disponível em:

<http://www.irtdpjbrasil.com.br/NEWSITE/pareceborba.htm. 07/07/2013>. Acesso em: 12 de agosto de 2015.

BRASIL. Código Civil. Lei no 10.406, de 10 de janeiro de 2002. Institui o Código Civil. Disponível em: <http://www.planalto.gov.br/ccivil_03/leis/2002/L10406.htm>. Acesso em: 13 de agosto de 2015.

BRASIL. Superior Tribunal de Justiça. Terceira Turma. Recurso Especial $n^{\circ}$ 1.266.666. Relatora: Ministra Nancy Andrighi . Brasília, 09/08/2011. DJe, Brasília, 25/08/2011.

BRASIL. Superior Tribunal de Justiça. Quarta Turma. Recurso Especial $n^{\circ}$ 1.227.240. Relator: Ministro Luis Felipe Salomão. Brasília, 26/05/2015. DJe, Brasília, 18/06/2015.

BRASIL. Superior Tribunal de Justiça. Quarta Turma. Recurso Especial $n^{\circ}$ 958.116. Relator: Ministro João Otávio Noronha. Brasília, 22/05/2012. DJe, Brasília, 06/03/2013.

CONSELHO DA JUSTIÇA FEDERAL. Jornadas de direito civil I, III, IV e V: Enunciados Aprovados / Coordenador científico Ministro Ruy Rosado de Aguiar Júnior. - Brasília: Conselho da Justiça Federal, Centro de Estudos Judiciários, 2012.

FIUZA, Ricardo. Novo Código Civil Comentado. São Paulo: Saraiva, 2003.

LE GOFF, JACQUES. Mercadores e Banqueiros da Idade Média. Tradução de Antônio de Pádua Danesi. São Paulo: Martins Fontes, 1991.

LE GOFF, JACQUES. Para uma Outra Idade Média. Tempo, trabalho e cultura no Ocidente. Tradução de Thiago de Abreu e Lima Florêncio e Noéli Correia de Melo Sobrinho. 2 ed. Petrópolis: Vozes, 2013.

MALATESTA, Alfonso Papa, L'imprenditore Commerciale. Roma: Giuffrè, 1998. MINAS GERAIS. Tribunal de Justiça de Minas Gerais. Agravo de Instrumento $n^{o}$ 
1.0024.09.498126-3/001. Relator Desembargador Generoso Filho. Belo Horizonte, 15/03/2011. DJMG, 04/04/2011.

ROULAND, Norbert. Nos Confins do Direito. Antropologia jurídica da modernidade. Tradução de Maria Ermantina de Almeida Prado Galvão. São Paulo: Martins Fontes, 2003.

SÃO PAULO. Tribunal de Justiça de São Paulo Apelação Cível $n^{\circ} 0035290$ 72.2006.8.26.0000. Relator: Pereira Calças. São Paulo, 2006. DJSP, 22/08/2006.

SÃO PAULO. Tribunal de Justiça de São Paulo. Agravo de Instrumento $n^{o} 2023917-$ 63.2013.8.26.0000. Relator: Francisco Loureiro. São Paulo, 05/12/2013. DJSP, 09/12/2013c.

SÃO PAULO. Tribunal de Justiça de São Paulo. Agravo de Instrumento n. 017095953.2013.8.26.0000. Relator: Francisco Loureiro. São Paulo, 06/02/2014. DJSP, 07/02/2014.

SÃO PAULO. Tribunal de Justiça de São Paulo. Agravo $n^{o}$ 311.752.4/0-00. Relator: Francisco Loureiro. São Paulo, 06/02/2014. DJSP, 07/02/2014.

SÃO PAULO. Tribunal de Justiça de São Paulo. Apelação Cível $n^{\circ} 0045261$ 62.2012.8.26.0100. Relator: Roberto Mac Cracken. São Paulo, 06/05/2013. DJSP, $13 / 05 / 2013 \mathrm{~b}$.

SÃO PAULO. Tribunal de Justiça de São Paulo. Apelação Cível no 0187821 36.2012.8.260000. Relator: José Reynaldo. São Paulo, 25/03/2013. DJSP, 28/03/2013a.

SÃO PAULO. Tribunal de Justiça de São Paulo. Apelação Cível $n^{\circ} 0122177-$ 84.2005.8.26.0100 . Relator: Enio Zuliani. São Paulo, 07/11/2013. DJSP, 12/11/2013d.

SÃO PAULO. Tribunal de Justiça de São Paulo. Apelação Cível $n^{\circ} 9196206-$ 92.2004.8.26.0000. Relator: Pereira Calças. São Paulo, 2005. DJSP, 08/09/2005.

SÃO PAULO. Tribunal de Justiça de São Paulo. Apelação Cível $n^{\circ}$ 990.10.092657-8. Romeu Ricupero. São Paulo, 04/05/2010. DJSP, 20/05/2010. 